\title{
Cost Optimization and Sensitivity Analysis of Composite Beams
}

\author{
Hamid Eskandari $^{\mathrm{a}^{*}}$, Tahereh Korouzhdeh $^{\mathrm{b}}$ \\ ${ }^{a}$ Assistant profossor, Department of Civil Engineering, Hakim Sabzevari University, Sabzevar, Iran \\ ${ }^{b}$ M.Tech student, Department of Civil Engineering, Hakim Sabzevari University, Sabzevar, Iran \\ Received 27 January 2016; Accepted 28 February 2016
}

\begin{abstract}
This study presents exact solution analysis for the cost optimization of Composite Beams (CB) based on the Load and Resistance Factor Design (LRFD) specifications. Matlab code formulation is applied to analysis of sensitivity for various parameters such as cost of concrete, steel beam, span length, concrete slab thickness, compressive strength of concrete, steel beams space and shear connectors on CB. Almost 20 thousands design were analysed to obtain various contour which be found that it is feasible, efficient and effective and capable in optimization of composite beam designs.
\end{abstract}

The obtained results represent that many of the contour are capable by achieving substantial cost savings for composite materials. Therefore, the analysis can be developed for practical designs to structural designers. A parametric study was also conducted to investigate the effects of IPE, IPB, INP profiles, UNP size and thickness of slabs and beam length on the cost optimization of CB.

Keywords: Composite Beam;Cost Optimization; Sensitivity Analysis.

\section{Introduction}

The design of composite beams is highly iterative and complicated which is depending on the design parameters a beam can be fully composite or partially composite. In the case of design has to consider plastic deformation on the basis of the LRFD and American Institute of Steel Construction (AISC) codes. Many researchers has been applied cost optimization of composite beam using prediction models such as neural dynamics, discrete using a floating point genetic algorithm, one way waffle slab and slab formwork using charged system search algorithm, social harmony, improved harmony search, ant colony system and genetic algorithm models [1-11]. Adeli and Kim [12] implemented genetic algorithm to cost optimization of composite floor. The total cost function includes the costs of concrete, steel beam, and shear connectors. And design was based on the AlSC and LRFD in the plastic design concepts. Based on a comparison with example designs presented could concluded that a formal cost optimization can result in substantial cost savings. In another one [13] three different materials: concrete, steel, and formwork used to minimize the cost as well as weight minimization which can be applicable for beams, slabs, columns, frame structures, bridges, water tanks, folded plates, shear walls, pipes, and tensile members. The concluded that life-cycle cost optimization of structures where the life-cycle cost of the structure over its lifetime is minimized instead of its initial cost of construction only.

In another view of this work due to sensitivity analysis of optimization is better to mention some work what has been done prior. There is some works on sensitivity analysis such as sensitivity analysis of reinforced concrete beams, composite floor systems channel-section and hollow-section trusses, design optimization of shell and tube heat exchangers, Structural optimization, honeycomb sandwich cylindrical columns under axial crushing loads, frequencies and modes for composite laminated structures, lateral-torsional buckling resistance of steel beams, machine repair problem and frequency sensitivity analysis for beams carrying lumped masses with translational and rotary inertias [14-23]. Hongbone is study the economic optimization and sensitivity analysis of photovoltaic system in residential

\footnotetext{
*Corresponding author: Hamidiisc@yahoo.com
} 
buildings which deals with optimal size of grid-connected photovoltaic (PV) system for residential application. He used simple linear programming model to minimize the annual energy cost of a given customer, including PV investment cost, maintenance cost, utility electricity cost, subtracting the revenue from selling the excess electricity. And the sensitivity of levelized cost and simple payback period to various economic and technical circumstances has been analyzed [24]. It also Castillo[25] introduces a new approach to composite breakwater design based on minimizing initial construction costs subject to yearly failure rate bounds for all failure modes, and presents a technique for sensitivity analysis. Due to complex optimization problem the evaluation of failure rates involves one optimization problem per failure mode, so that a decomposition method is used to solve the problem as well as sensitivity analysis is performed, to determine how the cost and yearly failure rates of the optimal solution are affected by small changes in the input data values.

Although many researches have been involved to composite structures optimization and sensitivity analysis problems but there are rarely literatures work that has been applied cost optimization along with sensitivity of composite beam. In practice, slab thickness and the number of shear studs are often chosen by engineers somewhat arbitrarily without any cost analysis due to times consuming.

In this research, Matlab code optimization design is written based LRFD to apply the exact solution to achieve an optimum solution out of numerous ones on the basis of a selected criterion such as minimum weight or minimum cost beams and sensitivity analysis of various design parameters are done too.

\section{Significance of the Investigation}

The purpose of this study is to provide a various contour maps which are useful since they provide valuable information about cost optimization of beam as well as sensitivity scrutinize and simplified for use of engineering in construction. The proposed method is based on Matlab code to analyze the various parameters which are effect on optimal cost and safety factor. However, for a particular input parameters such as IPE, IPB, INP profiles, UNP size and thickness of slabs and beam length and compressive strength, there is only one economical design, but with various safety factor. To study both of them to this research will be new idea may be useful.

Main objectives of present work are as following:

- A cost optimized for all combination of parameters which are around 28 thousands designs which only 20 thousands will satisfy the constraint.

- Contour of sensitivity analysis by assuming other parameters constant for various
a. Compressive strength of concrete
b. Thicknesses of slabs
c. Profile section of beams
d. UNPs size
e. Length of beams

\section{Design Parameters and Formulation}

The design parameters are formulated in two major steps: (1) to determine the effective decision variables which affecting the design of composite beams; and (2) to formulate the objective function. The notations of cost functions and constraints are listed respectively.

Beam span length $(L)$, slab thickness $(t c)$, compressive strength of concrete $(F c)$, steel beams space $\left(d_{c}\right)$, ultimate moment $\left(\mathrm{M}_{\mathrm{u}}\right)$, nominal moment $\left(\mathrm{M}_{\mathrm{n}}\right)$, depth of the equivalent stress block (a), the number of shear studs $(\mathrm{Ns})$, uniform service load $\left(\mathrm{W}_{\mathrm{L}}=0.02 \mathrm{~kg} / \mathrm{cm}^{2}\right)$, modules of elasticity for steel $\left(\mathrm{E}_{\mathrm{s}}=2100000 \mathrm{~kg} / \mathrm{cm}^{2}\right)$, modules of elasticity for concrete (e.g. $E_{c}=200000,250000$ and $300000 \mathrm{~kg} / \mathrm{cm}^{2}$ ), moment of inertia of the transformed fully composite section $\left(\mathrm{I}_{\mathrm{tr}}\right.$ ), a numeric coefficient such as $1 / 360\left(C_{1}\right)$, percentage of critical damping $(D=5)$, maximum initial amplitude of the floor system $\left(\mathrm{A}_{0}\right)$, first natural frequency of the floor system in $\mathrm{Hz}(\mathrm{f})$, gravitational acceleration $(\mathrm{g})$, effective depth of the slab $\left(\mathrm{d}_{\mathrm{e}}\right)$, the depth of steel section $(\mathrm{d})$, the yield strength $\left(\mathrm{F}_{\mathrm{y}}\right)$, cross-sectional area of steel $\left(\mathrm{A}_{\mathrm{s}}\right)$, modular ratio $(\mathrm{n})$, total horizontal shear force $\left(\mathrm{V}_{\mathrm{h}}\right)$, cross sectional area of shear connector $\left(\mathrm{A}_{\mathrm{unp}}\right)$, allowable shear force $\left(\mathrm{q}_{\text {all }}\right)$, width of shear connector $\left(\mathrm{L}_{\mathrm{u}}\right)$, service live load per unit length of the beam $\left(\Delta_{\mathrm{LL}}\right)$. A number of possible values for the five decision variables are given in Table 1. 
Table1. List of Possible Values for Variables

\begin{tabular}{|c|c|c|c|c|c|c|}
\hline Item & $F c\left(k g / \mathrm{cm}^{\wedge} 2\right)$ & $\operatorname{tc}(\mathbf{c m})$ & Profile's section & UNP size & $\mathbf{L}(\mathbf{c m})$ & Steel beam space $(\mathrm{cm})$ \\
\hline 0 & 200 & 8 & IPE 140 & 3 & 400 & 200 \\
\hline 1 & 300 & 10 & IPE 160 & 4 & 500 & \\
\hline 2 & 350 & 15 & IPE 180 & 5 & 600 & \\
\hline 3 & & 20 & IPE 200 & 6 & 700 & \\
\hline 4 & & & IPE 220 & 6.5 & 800 & \\
\hline 5 & & & IPE 240 & 8 & 900 & \\
\hline 6 & & & IPE 270 & 10 & 1000 & \\
\hline 7 & & & IPE 300 & 12 & 1100 & \\
\hline 8 & & & IPB 140 & 14 & 1200 & \\
\hline 9 & & & IPB 160 & 16 & & \\
\hline 10 & & & IPB 180 & & & \\
\hline 11 & & & IPB 200 & & & \\
\hline 12 & & & IPB 220 & & & \\
\hline 13 & & & IPB 240 & & & \\
\hline 14 & & & IPB 260 & & & \\
\hline 15 & & & IPB 280 & & & \\
\hline 16 & & & IPB 300 & & & \\
\hline 17 & & & INP 140 & & & \\
\hline 18 & & & INP 160 & & & \\
\hline 19 & & & INP 180 & & & \\
\hline 20 & & & INP 200 & & & \\
\hline 21 & & & INP 220 & & & \\
\hline 22 & & & INP 240 & & & \\
\hline 23 & & & INP 260 & & & \\
\hline 24 & & & INP 280 & & & \\
\hline 25 & & & INP 300 & & & \\
\hline
\end{tabular}

\subsection{Objective and Constraints Function}

The model is designed to measure the effect of different decision variables that includes in the cost optimization model of composite beams. So a total cost function is followed as below:

Minimize composite beam cost $=\mathrm{C}_{\mathrm{T}}=\mathrm{C}_{\mathrm{c}}+\mathrm{C}_{\mathrm{s}}+\mathrm{C}_{\mathrm{sd}}$

Where $\mathrm{C}_{\mathrm{c}}, \mathrm{C}_{\mathrm{s}}$, and $\mathrm{C}_{\mathrm{sd}}$ are the cost of concrete, steel beam, and shear connectors, respectively.

$\mathrm{C}_{\mathrm{T}}=\mathrm{Lbt}_{\mathrm{c}} \frac{\mathrm{C}_{\mathrm{c}}^{\prime}}{\mathrm{C}^{\prime}{ }_{\mathrm{s}}}+\rho \mathrm{A}_{\mathrm{s}} \mathrm{L}+\mathrm{G}_{\mathrm{unp}} l \mathrm{~N}_{\mathrm{s}} \frac{\mathrm{C}_{\mathrm{sd}}}{\mathrm{C}_{{ }_{\mathrm{s}}}}$

Where $\mathrm{L}$ is the beam span, $\rho$ is the unit weight of steel section, $C^{\prime}{ }_{c}$ (e.g. 20, 30 and 35\$) is the cost of concrete per unit weight, $C_{s}^{\prime}(0.9 \$)$ is the cost of the steel section per unit weight, $\mathrm{G}_{\text {unp }}$ is weight per unit length and $C^{\prime} s d(1 \$)$ is the cost of one shear connector including installation and material costs.

Using the notation of Figure 1, the calculations of composite beam elastic design are performed by the following relationships:

$$
\begin{aligned}
& \mathrm{M}_{\mathrm{n}}=\mathrm{A}_{\mathrm{s}} \mathrm{F}_{\mathrm{y}}\left(\frac{\mathrm{d}}{2}+\mathrm{t}_{\mathrm{c}}-\frac{\mathrm{a}}{2}\right) \\
& \mathrm{a}=\frac{\mathrm{A}_{\mathrm{s}} \mathrm{F}_{\mathrm{y}}}{0.85 \mathrm{f}^{\prime}{ }^{\mathrm{b}_{\text {eff }}}} \\
& \mathrm{b}_{\text {eff }}=\min \left(\frac{L}{4}, \mathrm{~d}_{\mathrm{c}}\right) \\
& \mathrm{b}_{1}=\frac{\mathrm{b}_{\text {eff }}}{n} \\
& \mathrm{n}=\frac{\mathrm{E}_{\mathrm{s}}}{\mathrm{E}_{\mathrm{c}}}
\end{aligned}
$$


$\bar{y}=\frac{\mathrm{A}_{\mathrm{s}} \frac{d}{2}+b_{1} t_{c}\left(d+\frac{t_{c}}{2}\right)}{\mathrm{A}_{\mathrm{s}}+b_{1} t_{c}}$
$\mathrm{I}_{\mathrm{tr}}=\mathrm{I}_{\mathrm{s}}+\mathrm{A}_{\mathrm{s}}\left(\overline{\mathrm{y}}-\frac{\mathrm{d}}{2}\right)+\frac{\mathrm{b}_{1}\left(\mathrm{~d}+\mathrm{t}_{\mathrm{c}}-\overline{\mathrm{y}}\right)^{3}}{12}+\frac{\mathrm{b}_{1}\left(\mathrm{~d}+\mathrm{t}_{\mathrm{c}}-\overline{\mathrm{y}}\right)^{3}}{4}$

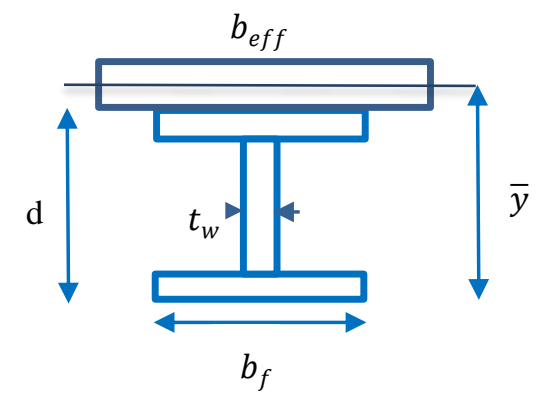

Figure 1. Composite Beam Elastic Design Construction

When the plastic neutral axis (PNA) lies within the beam flange as shown in Figure 2, the following equations can be applied:

$$
\begin{aligned}
& \bar{y}=\frac{A_{s} F_{y}-0.85 f_{c} b_{e f f} t_{c}}{2 F_{y} b_{f}} \\
& I_{t r}=I_{s}+A_{s}\left(\frac{d}{2}-\bar{y}\right)^{2}+\frac{b_{e f f} t_{c}{ }^{3}}{12}+b_{e} t_{c}\left(\frac{F_{y} A_{s}-0.85 f_{c} b_{e f f} \frac{e_{c}}{e_{s}} t_{c}}{2 F_{y} b_{f}}+t_{c}-\frac{A_{s} F_{y}}{0.85 f_{c} b_{e f f} \frac{e_{c}}{e_{s}} \times 2}\right)^{2} \\
& M_{n-\text { composite }}=f_{c} b_{\text {eff }} t_{c}\left(\frac{t_{c}}{2}+\bar{y}\right)+2 F_{y} b_{f} \bar{y} \frac{\bar{y}}{2}+F_{y} A_{s}\left(\frac{d}{2}-\bar{y}\right) \\
& \Delta_{L L}=\frac{5 w_{L L} l^{4}}{384 E_{s} I_{t r}}
\end{aligned}
$$

For calculation of the number of UNPs, the following equations can be used.

$$
\begin{aligned}
& \mathrm{V}_{\mathrm{h}}=\min \left(0.85 \times \mathrm{f}^{\prime}{ }_{\mathrm{c}} \times \mathrm{b}_{\text {eff }} \times \frac{\mathrm{t}_{\mathrm{c}}}{2},\left(\mathrm{~A}_{\mathrm{s}}+\mathrm{A}_{\mathrm{unp}}\right) \times \frac{\mathrm{F}_{\mathrm{y}}}{2}\right) \\
& \mathrm{q}_{\text {all }}=0.3 \times\left(\mathrm{t}_{\mathrm{f}}+0.5 \mathrm{t}_{\mathrm{w}}\right) \mathrm{L}_{\mathrm{u}} \sqrt{\mathrm{f}_{\mathrm{c}} \mathrm{E}_{\mathrm{c}}} \\
& \mathrm{N}_{\mathrm{s}}=\frac{\mathrm{V}_{\mathrm{h}}}{\mathrm{q}_{\text {all }}}
\end{aligned}
$$

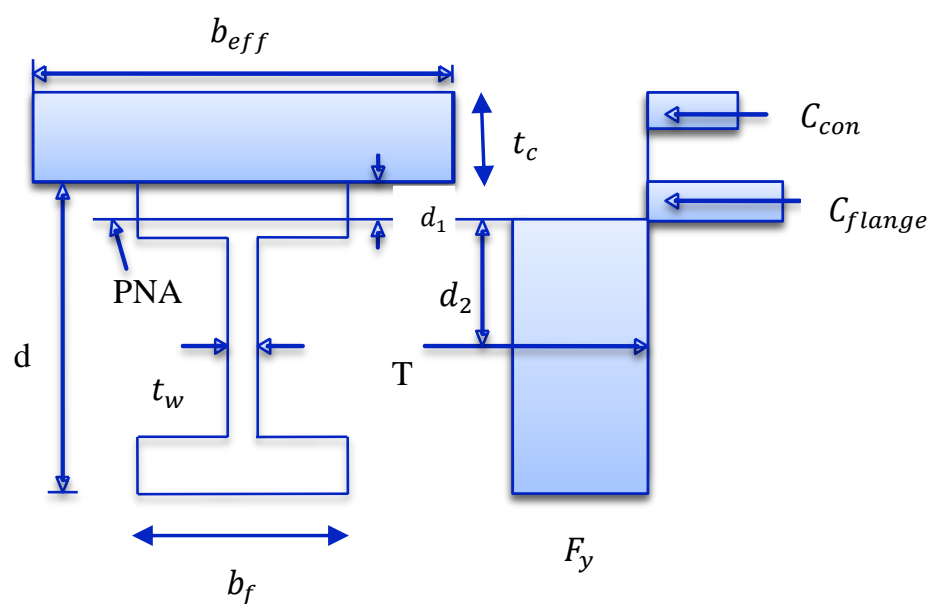

Figure 2. Plastic Design of Composite Beams When PNA Lies in Steel Flange

The moment capacity of the composite section to investigate the ability of taking all dead and live loads must be checked as defined by the following constraint: 
$\frac{M_{u-\text { composite }}}{0.85 M_{n \text {-composite }}}-1 \leq 0$

The deflection of the composite beam due to live loads, $\mathrm{W}_{\mathrm{LL}}$ is given by

$\frac{\Delta_{\mathrm{LL}}}{\mathrm{c}_{1} \mathrm{~L}}-1 \leq 0$

Vibration response floor for AISD-LRFD code an expression of a damping ratio:

$\frac{35 A_{0} f+2.5}{D}-1 \leq 0$
$\mathrm{f}=1.57\left(\frac{\mathrm{gE}_{\mathrm{S}} \mathrm{I}_{\mathrm{tr}}}{\mathrm{WL}^{3}}\right)^{0.5}$

$A_{0}= \begin{cases}A_{1} & \text { when } t_{0} \geq 0.05 \\ A_{2} & \text { when } t_{0}<0.05\end{cases}$

$\mathrm{A}_{1}=\frac{1}{\mathrm{~N}_{\mathrm{eff}}}\left(0.246 \mathrm{~L}^{3} \frac{0.1-\mathrm{t}_{0}}{\mathrm{E}_{\mathrm{s}} \mathrm{I}_{\mathrm{tr}}}\right)$

$A_{2}=\frac{1}{N_{\text {eff }}}\left[\frac{0.246 \mathrm{~L}^{3}}{E_{\mathrm{s}} \mathrm{I}_{\mathrm{tr}}}\left\lfloor\frac{1}{2 \pi \mathrm{f}} \sqrt{2(1-\alpha \sin \alpha-\cos \alpha)+\mathrm{a}^{2}}\right]\right]$

$\mathrm{t}_{0}=\frac{1}{\pi \mathrm{f}} \tan ^{-1} \alpha \quad$ and $\alpha=0.1 /(\pi \mathrm{f})$

$\mathrm{N}_{\text {eff }}=2.967-0.05776 \frac{\mathrm{b}}{\mathrm{d}_{\mathrm{e}}}+2.556 \times 10^{-8} \frac{\mathrm{L}^{4}}{\mathrm{I}_{\mathrm{tr}}}+0.0001\left(\frac{\mathrm{L}}{\mathrm{b}}\right)^{3} \geq 1.0$

Maximum centre to centre spacing of shear connectors not to be greater than eight times the total slab thickness, tc, i.e.

$\frac{\text { stud_spacing }}{8 \times t_{c}}-1 \leq 0$

\section{Model and Flow Chart Implementation}

In this cost optimisation, a very large data of analysis is achieved from exact solution, which can be used for the implementation of the contours and sensitivity analysis, and optimization tools can assist decision type to identifying optimal or near optimal solutions. Figure 3 shows how exact solution which are clear that there are six distinct stages in this flowchart, from the initial collection of various parameters such as profiles types, $\mathrm{Fc}$, tc, beam span and UNP size to the eventual optimal cost and safety. At the first stage in the flowchart diagram process, all input parameters are collected together cost as well as other properties which may affect the design procedure such as area, moment inertia, high, and length of flange, web and other properties of profiles. This flowchart is then based on two types of standards design of LRFD analysis of design has been done the number of design which are has been done here are around 28 thousands. Next, the all number of design should be satisfying the all constrained. Stages four and five of the process both involves satisfied constraint and cost computing which are around 20 thousands designs. The stages of six and seven are plotting contour to analysis of sensitivity along with safety factor which safety factor is defined as maximum moment capacity of design divided to moment capacity of beam which is fixed for design $(0<M u / 0.85 M n<1)$. So that the safety value closer to lower limit, have higher safety factors. Finally, the achieved contours can be processed to design of composite beam, which may satisfy the maximum safety and optimal cost together.

\section{Sensitivity Analysis and Discussion}

An efficient optimization exact model is suggested to perform the cost optimization of composite beam. This work is the present a simple and efficient exact solution that can be used in practical engineering problem instead of predictions model such as artificial neural network and genetic algorithm. Sensitivity analysis is performed for the cost of composite beam design. Sensitivity analysis of various parameters in composite beam designing has been implemented also to apprehend which parameters play more important roles for having better design circumstances. Since performing sensitivity analysis of whole design parameters (Fc, tc, Ns, profile size and UNP size) on cost and 
safety factor isn't that easy, for this reason one or some of design parameters have been kept constant and according to the contours have been drawn can be evaluated the influence of other parameters on cost and safety factor.

Figure 4 compares the costs depending on beam span for three variables as numbers of UNPs (Ns), safety and profiles number such as INP, IPE and IPB. Some of design parameters such as UNP size, slab thickness and as well as compressive strength have been considered as constant values. It is notable that in INP, IPE and IPB diagrams up to $50 \%$ over design are not in limit response.

In general, by increasing both the Ns and size of profile as well as beam span, total cost increased too. Moreover, it can be reputed out that size of profile is the most effective parameter on raising cost than to Ns due to having exactly similar trends which may understood that Ns are not that much sensitive to beam span. Since the curves related to each of design parameters such as Ns and sizes of profiles after specific points continue as straight lines, it may be found that, these points are the maximum limits for considering them in designs. For example for all three INP, and IPE and IPB profiles with $900 \mathrm{~cm}$ beam span, the first profile's number is 18,20 and 14 respectively with design costs of $240 \$$ for INP and IPE and 335 \$ for IPB. Then, amounts of over designs are 14, 20 and 35\% respectively.

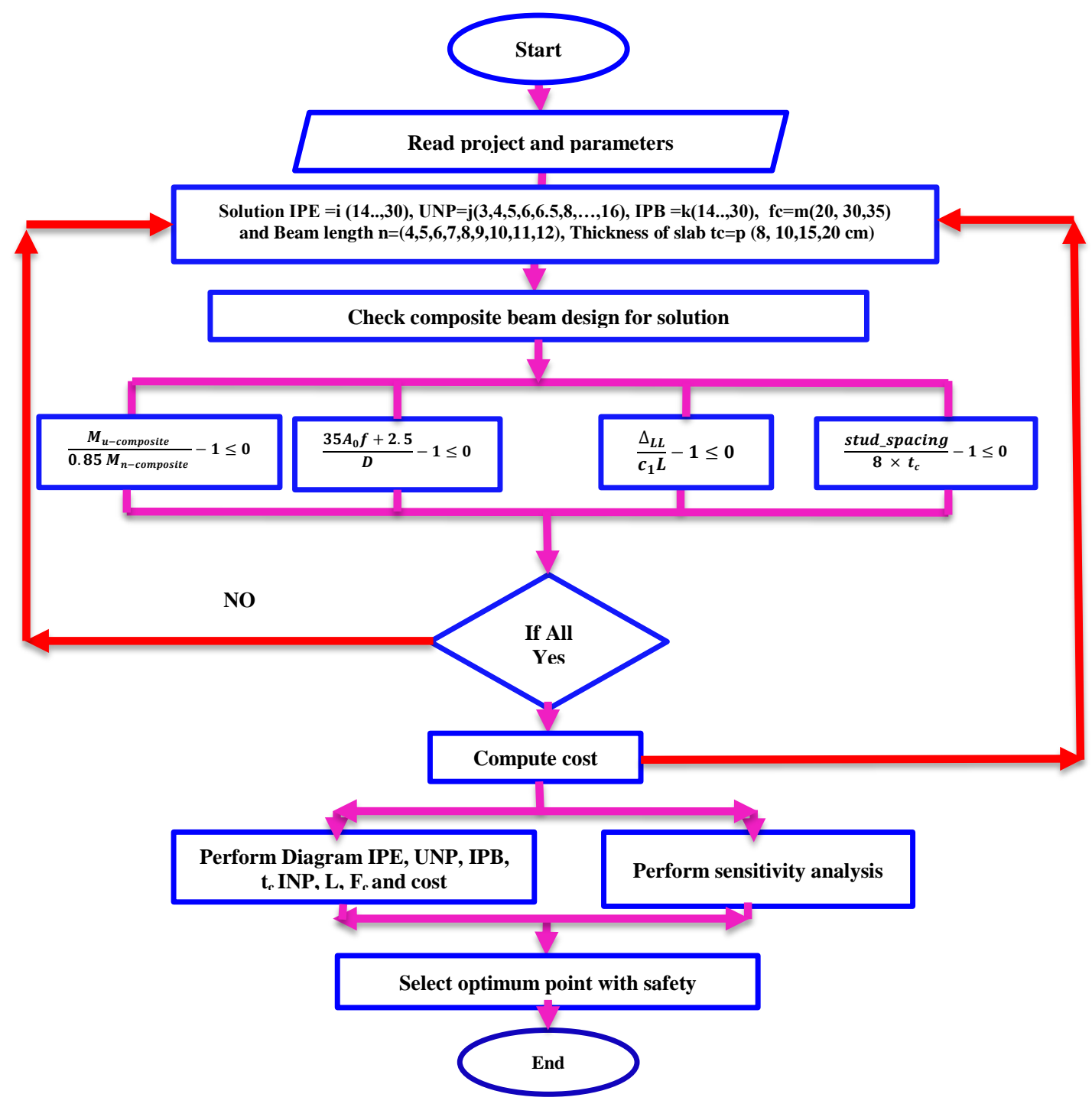

Figure 3. Flow Chart of Composite Beam Cost Optimization 

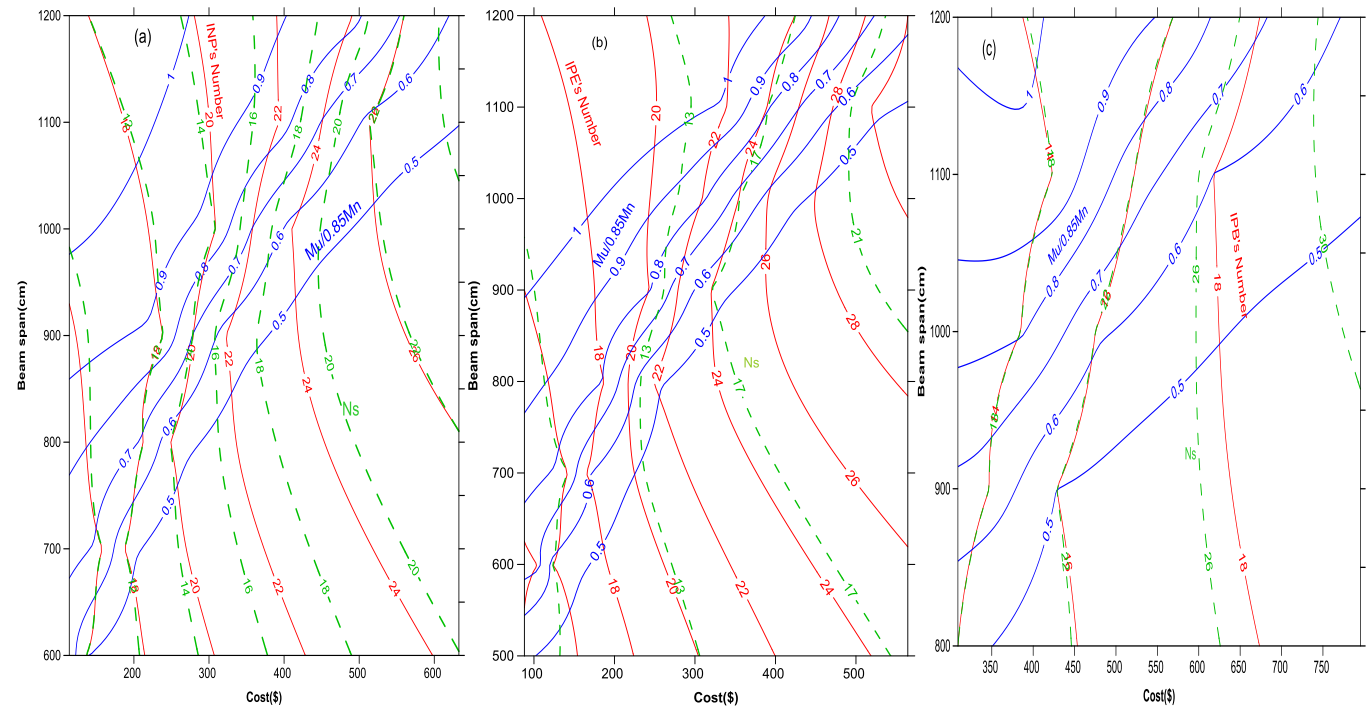

Figure 4. Sensitivity Analysis of Cost Function With Respect to Beam Span, Size of Steel Profile, Ns and Safety for Various Steel Profiles $(\mathrm{UNP}$ size $=3, \mathrm{Fc}=\mathbf{2 0 0}, \mathrm{tc}=\mathbf{1 0})$

Thus, selecting suitable profile should be done due to various available conditions and also expected safety factors. In this regard, by considering a constant profile size, minimum costs according to regulation's constraints, increased by moving from IPE to IPB profile while their safety factors are almost constant. For example in constant profile size of 18, minimum costs are 185, 165 and 620 with 43, 38 and 40\% over design as safety factor for INP, IPE and IPB respectively. Consequently, exerting IPE profile could be optimal in these similar situations. Subsequently various parameters which may affect designing composite beams using IPE profile, such as size of profiles, slab thickness, compressive strength of concrete, number of UNP (Ns) and also safety factor are investigated. Here the interaction of beam span and cost along with safety factor considering steel beam (IPE) size (a), the Fc and Ns values (b) and amount of tc (c) are depicted in Figure 5. The contours are being worthwhile for selecting the steel beam size, Fc, Ns and tc for various beam spans considering the optimal cost along with safety. The zone of truthful response is belonging to interaction area of the contours which relate to safety factors of between 1 as the optimal design and 1.5 as $50 \%$ over design. Considering these three contours beside each other shows by increasing the beam span, the size of profile as well as total cost is increased and it's obvious that safety factor is more influenced by these three parameters. For example, by applying IPE size of 18 and increasing beam span from 800 to $1000(\mathrm{~cm})$, the cost is increased about $25 \%$ and the safety factor (over design value) will be decreased around $22 \%$ while the other parameters like tc and fc are almost constant. As seen, enhancing the Fc and Ns leads to increasing in cost and safety factor. However, by considering a constant beam span like $1000 \mathrm{~cm}$ and applying IPE 18 it should be better to select Fc as $200 \mathrm{~kg} / \mathrm{cm}^{2}$ with safety factor of 1.1 for having optimal cost of $250 \$$. With similar situations using $300 \mathrm{~kg} / \mathrm{cm}^{2}$ as fc instead of 200 $\mathrm{kg} / \mathrm{cm}^{2}$ leads to the increasing in cost about $60 \%$ against the safety factor with only $32 \%$ improvement which may not be optimal. Similarly, this type of contours may be useful to demonstrate the relationships of steel beam size, Fc, Ns, tc, cost and safety factor for various beam spans in order to choosing the most appropriate design condition.
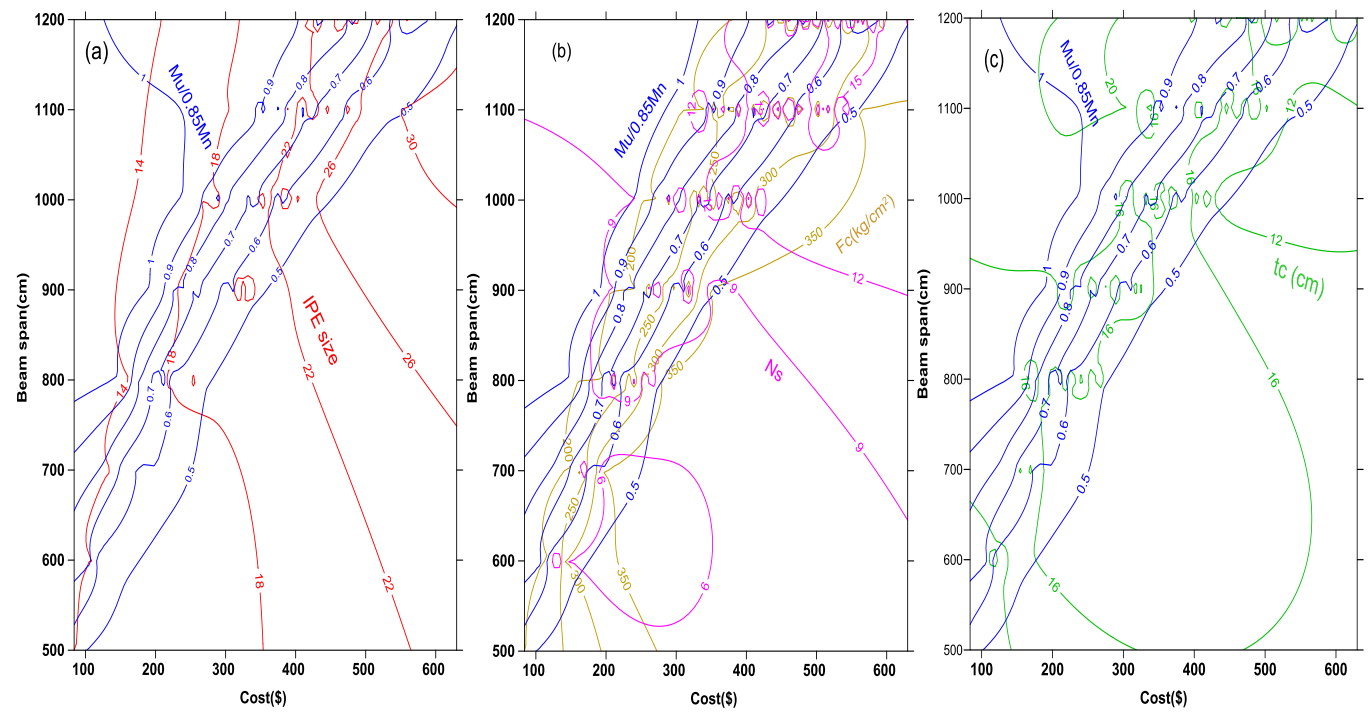

Figure 5. Sensitivity Analysis of Cost Functions vs. Beam Span, by Various IPE Size (a), Fc And Ns (b) and Slab Thickness (c) for Constant UNP Size $=3$ 
Performing sensitivity analysis of whole design parameters (Fc, tc, Ns, IPE and UNP size) on cost and safety factor isn't that easy due to several parameters affect simultaneously on composite beam design based on LRFD specifications. To simplify that, the sensitivity analysis contours depicted in Figure 6 which belong to the beam IPE 14 for various parameters such as UNP size, tc, Fc, Ns, beam span and cost along with safety factor. As seen, typically for each beam span there are many selection based the requirements so that increasing the UNP size is followed by decreasing in Ns and increasing in total cost, tc, Fc and also safety factor. For example for constant beam span of 600 $\mathrm{cm}$, the optimal choice for values of design parameters are 3, 8, 10 and 200 for UNP size, Ns, tc and Fc respectively along with safety factor of 1.3 with cost of 110 \$. It can be mentioned here applying these contours for other IPE sizes, the optimal selection of UNP size, Ns, Fc, tc and cost along with safety factor can be identified also.

All the above contours is study the sensitivity of various parameters on span beam and cost under safety zone of 0.5 to 0.9 that means the 100 to $10 \%$ over design respectively. To magnify the safety factor the contour for varies parameters safety, Fc, IPE and UNP size, span beam, tc constant cost is depicted in Figure 7. As realized in this contour can valuable to identify the optimal cost along with safety factor for constants spam beam, UNP, tc are 1200 $\mathrm{cm}, 10,20$ respectively. For illustrated if constant cost is assumed 500\$ can there are two design one by IPE22, Fc 300, Ns 8 and safety factor 1.2 and another by IPE 24, Fc 200, Ns 12 and safety factor 1.35 which can concluded that the sensitivity of safety is more affect by IPE number compare to Fc. In other hand by obtaining for all span beams the any engineer designer can be identify the optimum solution of design as well as cost.
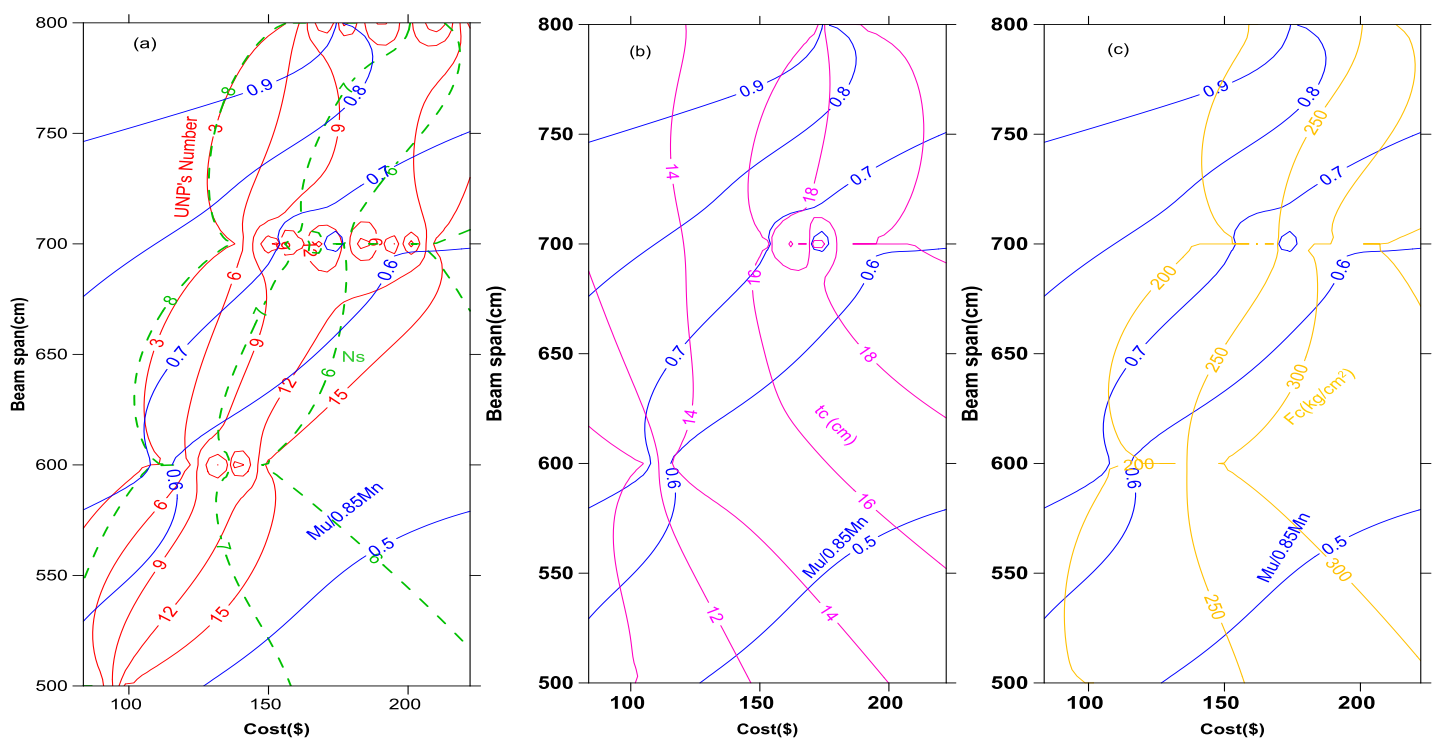

Figure 6. Sensitivity Analysis of Cost Functions vs. Beam Span, by Various UNP Size and Ns (a), tc (b) and Fc (c) for Constant IPE Size $=14$

Additionally by assume constant safety factor 1.1 that means $10 \%$ over design, and other parameter varies for the optimal design the analysis are come in contour which is shown in Figure 8. This figure can be used directly for any span beam as well as varies other parameters which can be identifying the optimal cost. For illustrated constant safety, tc and Fc the optimal design, for span beam of 900, 1000, 1100, 1200 the IPE and UNPs size and cost will be, 16,18,20, 22 and 3 to 16 and 200,260, 325, 400\$ respectively. 


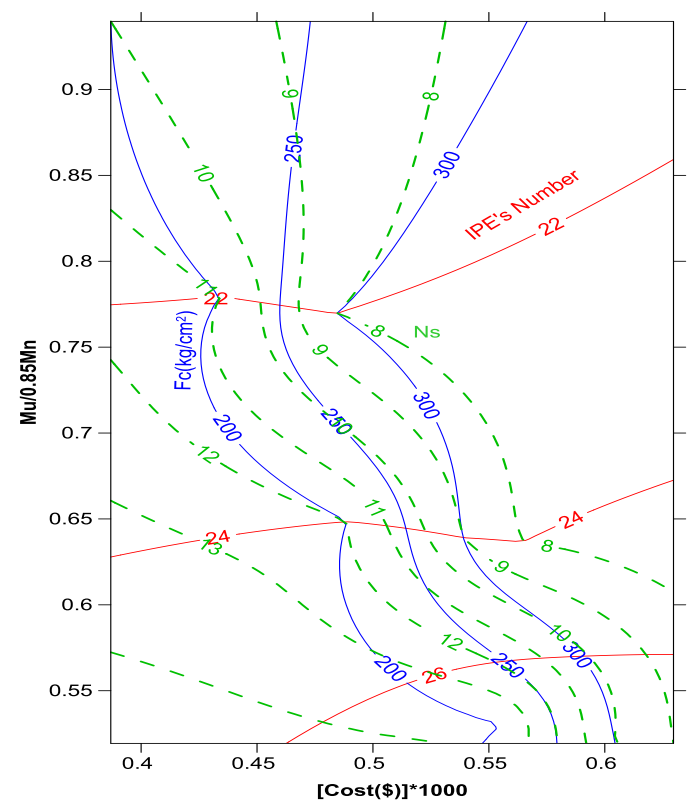

Figure 7. Sensitivity Analysis of Cost Functions vs. Safety Factor, by Various IPE Size, Compressive Strength and Ns, tc=20, UNP size $=10$ and Beam $S p a n=1200 \mathrm{~cm}$

Finally, comparing whole diagrams suggested that for a constant beam span and without any significant reduction in safety factors, minimum total cost is related to IPE design parameters. For example by considering $1000 \mathrm{~cm}$ as beam span, total costs are 390, 360 and 470 \$ for applying INP, IPE and IPB respectively which suggested that IPE profiles may be optimal sections in the cost point of view. The interactions of various design parameters such as cost, beam span, tc and safety factor have been depicted in Figure 6 to compare them in different situations of using IPE, INP and IPB as steel sections. By scrutinizing the diagrams, it can be deduced that for each constant beam span, increasing the tc from 10 to $20 \mathrm{~cm}$ generally shows similar trends in total cost growth. Thus, it may be understood that

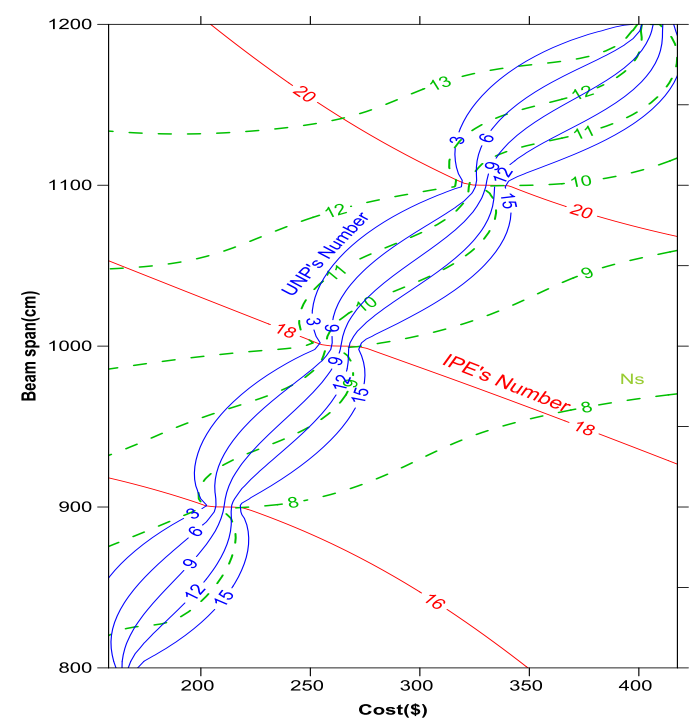

Figure 8. Sensitivity Analysis of Cost Function With Respect to Beam Span, for Various UNP Size, Ns, IPE's

Number $(\mathrm{Fc}=200, \mathrm{tc}=15, \mathrm{Mu} / 0.85 \mathrm{Mn}>0.9)$.

the cost don't have any noticeable sensitivity in changing the tc. Furthermore, each of these slab thicknesses due to satisfying whole constraints might be used up to a limit beam span. For example, tc $=10$ should not be applied for more than 700, 800 and $1200 \mathrm{~cm}$ in IPE, INP and IPB profiles respectively.

\section{Conclusion}

An efficient optimization exact model is proposed to perform the cost optimization of composite beam which are reliant on concrete slab and steel profiles beams along with UNP profiles. This work is mostly aimed to present a simple and efficient exact solution that can be applied in practical engineering problems instead of predictions model such as artificial neural network and genetic algorithm. The outcomes specifically indicate that: 
- The model is enabled to specify the safe optimal point of design as well as cost optimal based on LRFD code for illustration by considering the safety and optimal cost point of view, the IPB and IPE profile may be selected respectively for a constant condition.

- The sensitivity of each three INP, IPE and IPB profiles could be obtained due to various particular conditions of designing. So the analysis can be developed for practical structural designs.

- By considering a constant profile size, minimum costs according to regulation's constraints, increased by moving from IPE to INP and INP to IPB profile while their safety factors are almost constant.

- The result obtained show that safety factor is more influenced by the beam span, the size of profiles and total cost that other than design parameters.

- Due to the sensitivity analysis performed can be seen that IPE profile is more economical than other profiles in the constant conditions.

- Finally, applying sensitivity analysis for Ns and UNP size, it can be deduced that UNP size is more sensitive on optimal cost at constant safety; in another word it is better in the constant condition to select lower UNP size along with more Ns which contains optimal cost.

\section{References}

[1] KIM, HONGJIN, and HOJJAT ADELI. "Discrete cost optimization of composite floors using a floating-point genetic algorithm." Engineering Optimization 33, no. 4 (2001): 485-501.

[2] Kaveh, A., and A. F. Behnam. "Cost optimization of a composite floor system, one-way waffle slab, and concrete slab formwork using a charged system search algorithm." Scientia Iranica 19, no. 3 (2012): 410-416.

[3] Kaveh, A., and M. Ahangaran. "Discrete cost optimization of composite floor system using social harmony search model." Applied Soft Computing 12, no. 1 (2012): 372-381.

[4] Kaveh, A., and M. S. Massoudi. "Cost optimization of a composite floor system using ant colony system." Iranian Journal of Science and Technology, Transactions of Civil Engineering 36, no. C2 (2012): 139-148.

[5] Klanšek, U., and S. Kravanja. "Cost estimation, optimization and competitiveness of different composite floor systems-part 1: self-manufacturing cost estimation of composite and steel structures." Journal of Constructional Steel Research 62, no. 5 (2006): 434-448.

[6] Wang, Kuo-Hsiung, Yuh-Ching Liou, and Dong-Yuh Yang. "Cost optimization and sensitivity analysis of the machine repair problem with variable servers and balking." Procedia-Social and Behavioral Sciences 25 (2011): 178-188. [7] Kravanja, Stojan, and Simon Šilih. "Optimization based comparison between composite I beams and composite trusses." Journal of constructional steel research 59, no. 5 (2003): 609-625.

[8] Jármai, Károly, and Jozsef Farkas. "Cost calculation and optimisation of welded steel structures." Journal of Constructional Steel Research 50, no. 2 (1999): 115-135.

[9] Kaveh, A., and A. Shakouri Mahmud Abadi. "Cost optimization of a composite floor system using an improved harmony search algorithm." Journal of Constructional Steel Research 66, no. 5 (2010): 664-669.

[10] Senouci, Ahmed B., and Mohammed S. Al-Ansari. "Cost optimization of composite beams using genetic algorithms." Advances in Engineering Software 40, no. 11 (2009): 1112-1118.

[11] Sarma, Kamal C., and Hojjat Adeli. "Fuzzy discrete multicriteria cost optimization of steel structures." Journal of structural engineering 126, no. 11 (2000): 1339-1347.

[12] Adeli, Hojjat, and Hongjin Kim. "Cost optimization of composite floors using neural dynamics model." Communications in Numerical Methods in Engineering 17, no. 11 (2001): 771-787.

[13] Sarma, Kamal C., and Hojjat Adeli. "Cost optimization of concrete structures." Journal of Structural Engineering 124, no. 5 (1998): 570-578.

[14] Koo, Kunmo, Roberto D’Amico, Bert Pluymers, and Wim Desmet. "Design sensitivity analysis and optimization of frequency averaged input power using the residue theorem." Computers \& Structures 145 (2014): 58-71.

[15] Coronado, Carlos A., and Maria M. Lopez. "Sensitivity analysis of reinforced concrete beams strengthened with FRP laminates." Cement and Concrete Composites 28, no. 1 (2006): 102-114.

[16] Mínguez, Roberto, Enrique Castillo, Carmen Castillo, and Miguel A. Losada. "Optimal cost design with sensitivity analysis using decomposition techniques. Application to composite breakwaters." Structural Safety 28, no. 4 (2006): 321-340.

[17] Castillo, Enrique, Roberto Mínguez, and Carmen Castillo. "Sensitivity analysis in optimization and reliability problems." Reliability Engineering \& System Safety 93, no. 12 (2008): 1788-1800.

[18] Saleeb, A. F., T. E. Wilt, N. R. Al-Zoubi, and A. S. Gendy. "An anisotropic viscoelastoplastic model for compositessensitivity analysis and parameter estimation." Composites Part B: Engineering 34, no. 1 (2003): 21-39.

[19] Fesanghary, M., E. Damangir, and I. Soleimani. "Design optimization of shell and tube heat exchangers using global 
sensitivity analysis and harmony search algorithm." Applied Thermal Engineering 29, no. 5 (2009): 1026-1031.

[20] Allaire, Grégoire, François Jouve, and Anca-Maria Toader. "Structural optimization using sensitivity analysis and a level-set method." Journal of computational physics 194, no. 1 (2004): 363-393.

[21] Ebrahimi, Saeed, and Nader Vahdatazad. "Multiobjective optimization and sensitivity analysis of honeycomb sandwich cylindrical columns under axial crushing loads." Thin-Walled Structures 88 (2015): 90-104.

[22] Liu, Qimao. "Analytical sensitivity analysis of frequencies and modes for composite laminated structures." International Journal of Mechanical Sciences 90 (2015): 258-277.

[23] Kala, Z. "Sensitivity and reliability analyses of lateral-torsional buckling resistance of steel beams." Archives of Civil and Mechanical Engineering 15, no. 4 (2015): 1098-1107.

[24] Ren, Hongbo, Weijun Gao, and Yingjun Ruan. "Economic optimization and sensitivity analysis of photovoltaic system in residential buildings." Renewable energy 34, no. 3 (2009): 883-889.

[25] Castillo, C., R. Mínguez, E. Castillo, and M. A. Losada. "An optimal engineering design method with failure rate constraints and sensitivity analysis. Application to composite breakwaters." Coastal Engineering 53, no. 1 (2006): 1-25. 